\title{
Reusability Studies for Ares I and Ares V Propulsion
}

\author{
Thomas J. Williams ${ }^{1}$ and Alex S. Priskos ${ }^{2}$ \\ NASA Marshall Space Flight Center, MSFC, AL, 35812 \\ Andrew A. Schorr ${ }^{3}$ \\ NASA Marshall Space Flight Center, MSFC, AL, 35812 \\ and \\ Greg Barrett ${ }^{4}$ \\ NASA Marshall Space Flight Center, MSFC, AL, 35812
}

\begin{abstract}
With a mission to continue to support the goals of the International Space Station (ISS) and explore beyond Earth orbit, the United States National Aeronautics and Space Administration (NASA) is in the process of launching an entirely new space exploration initiative, the Constellation Program. Even as the Space Shuttle moves toward its final voyage, Constellation is building from nearly half a century of NASA spaceflight experience, and technological advances, including the legacy of Shuttle and earlier programs such as Apollo and the Saturn V rocket. Out of Constellation will come two new launch vehicles: the Ares I crew launch vehicle and the Ares V cargo launch vehicle. With the initial goal to seamlessly continue where the Space Shuttle leaves off, Ares will firstly service the Space Station. Ultimately, however, the intent is to push further: to establish an outpost on the Moon, and then to explore other destinations. With significant experience and a strong foundation in aerospace, NASA is now progressing toward the final design of the First Stage propulsion system for the Ares I. The new launch vehicle design will considerably increase safety and reliability, reduce the cost of accessing space, and provide a viable growth path for human space exploration. To achieve these goals, NASA is taking advantage of Space Shuttle hardware, safety, reliability, and experience. With efforts to minimize technical risk and life-cycle costs, the First Stage office is again pulling from NASA's strong legacy in aerospace exploration and development, most specifically the Space Shuttle Program. Trade studies have been conducted to evaluate life-cycle costs, expendability, and risk reduction. While many first stage features have already been determined, these trade studies are helping to resolve the operational requisites and configuration of the first stage element. This paper first presents an overview of the Ares missions and the genesis of the Ares vehicle design. It then looks at one of the most important trade studies to date, the "Ares I First Stage Expendability Trade Study.” The purpose of this study was to determine the utility of flying the first stage as an expendable booster rather than making it reusable. To lower the study complexity, four operational scenarios (or cases) were defined. This assessment then included an evaluation of the development, reliability, performance, and transition impacts associated with an expendable solution. This paper looks at these scenarios from the perspectives of cost, reliability, and performance.
\end{abstract}

${ }^{1}$ Propulsion Systems Manager, Ares Projects, MSFC, AL, 35812.

${ }^{2}$ First Stage Element Manager, Ares Projects, JP20, MSFC, AL, 35812.

${ }^{3}$ Lead, Ares First Stage Five Segment Motor (RSRMV), Ares Projects, JP20, MSFC, AL, 35812.

${ }^{4}$ FITO and Ares V Business Manager, Ares Projects, MSFC, AL, 35812. 


\section{Nomenclature}

\begin{tabular}{|c|c|c|c|}
\hline$B D M$ & $=$ Booster Deceleration Motor & $\mathrm{lbm}$ & Pounds of Mass \\
\hline BTM & Booster Tumble Motor & $L O C$ & Loss of Crew \\
\hline $\mathrm{CaLV}$ & Cargo Launch Vehicle & $L O M$ & Loss of Mission \\
\hline$C D F$ & Confined Detonating Fuse Line & Max G & Maximum Gravity \\
\hline$C D R$ & Critical Design Review & $\operatorname{Max} Q$ & Maximum Dynamic Pressure \\
\hline CEV & Crew Exploration Vehicle & MEOP & Maximum Expected Operating Pressure \\
\hline$C L V$ & Crew Launch Vehicle & Mlbf-sec & Million pounds of force per second \\
\hline CM/LAS & $\begin{array}{l}=\text { Command Module/Launch Abort System } \\
=\text { simulator })\end{array}$ & $\begin{array}{l}\text { MSFC } \\
m T\end{array}$ & $\begin{array}{l}=\text { Marshall Space Flight Center } \\
=\text { Metric Ton (Tonne) }\end{array}$ \\
\hline$D A C$ & Design Analysis Cycle & NASA & National Aeronautics and Space \\
\hline$D D T \& E$ & Design, Development, Test, and & & Administration \\
\hline & Evaluation & $O \& M$ & Operations and Maintenance \\
\hline DFI & Developmental Flight Instrumentation & $O M L$ & Outer Mold-line \\
\hline$D M$ & Development Motor & $P B A N$ & Polybutadiene Acrylonitrile \\
\hline EDS & Earth Departure Stage & PFAR & Post-Flight Assessment Report \\
\hline ELP & Exploration Launch Projects & PFI & Post Flight Inspection \\
\hline ESAS & Exploration Systems Architecture Study & PRACA & Problem Assessment and Corrective \\
\hline FMEA & Failure Modes and Effects Analysis & & Action \\
\hline FITO & Flight and Integrated Test Office & PSA & Production Simulation Article \\
\hline FS & First Stage & $p s f$ & Pounds Per Square Foot \\
\hline FSE & Forward Skirt Extension & psi & Pounds Per Square Inch \\
\hline FSM & Flight Support Motor & psia & Pounds Per Square Inch Absolute \\
\hline FTS & $=$ Flight Termination System & $R S R B$ & Reusable Solid Rocket Booster \\
\hline FWC & Filament Wound Case & $S R B$ & Solid Rocket Booster \\
\hline GSE & Ground Support Equipment & $S R M$ & Solid Rocket Motor \\
\hline ISS & International Space Station & SSME & Space Shuttle Main Engine \\
\hline IS & Interstage & $T L I$ & Trans-Lunar Injection \\
\hline JSC & Johnson Space Center & TPS & Thermal Protection System \\
\hline KSC & Kennedy Space Center & TVC & Thrust Vector Control \\
\hline LAS & $=$ Launch Abort System & US & Upper Stage \\
\hline LEO & $=$ low-Earth Orbit & USE & Upper Stage Engine \\
\hline
\end{tabular}

\section{Introduction: Ares Overview}

Tor the first time in over thirty years, NASA is developing a new fleet of human rated space flight vehicles. - NASA's Marshall Space Flight Center (MSFC) in Huntsville, Alabama, has been assigned that mission. Tasked with delivering new crew and cargo launch capabilities, going not just to the Moon, but reaching further to build and explore from a lunar outpost, safely deliver a payload of crew and cargo to a specified ascent target and extend the boundaries of human exploration beyond low-Earth orbit (LEO). Reaching these goals, and expanding these capabilities will entail two separate missions:

1) The crew and cargo will be separated into two separate vehicles: Ares I and Ares V (Figure 1) respectively. The Ares vehicles will seamlessly continue service to the International Space Station (ISS), transporting both people and payloads in a similar manner to, and as a direct continuation of, current Space Shuttle operations, which will be phased out as the new vehicles are phased in.

2) In parallel with, and as part of the design of these new Ares vehicles, will be the delivery of new transport and crew exploration vehicles. The crew exploration vehicle, Orion, will have the capability to dock with both ISS and the Altair (the fleet's new lunar lander), providing the ability to deliver both crew and cargo to the Moon and beyond. Equipped with a launch abort system, Orion will be capable of pulling its crew to safety in the event of an emergency on the launch pad or at any time during ascent. In addition to cargo, it will be able to deliver up to four crewmembers to the Moon's surface, and serve as a base for exploration for up to a week, thereby providing the capability to explore further in subsequent lunar missions. 


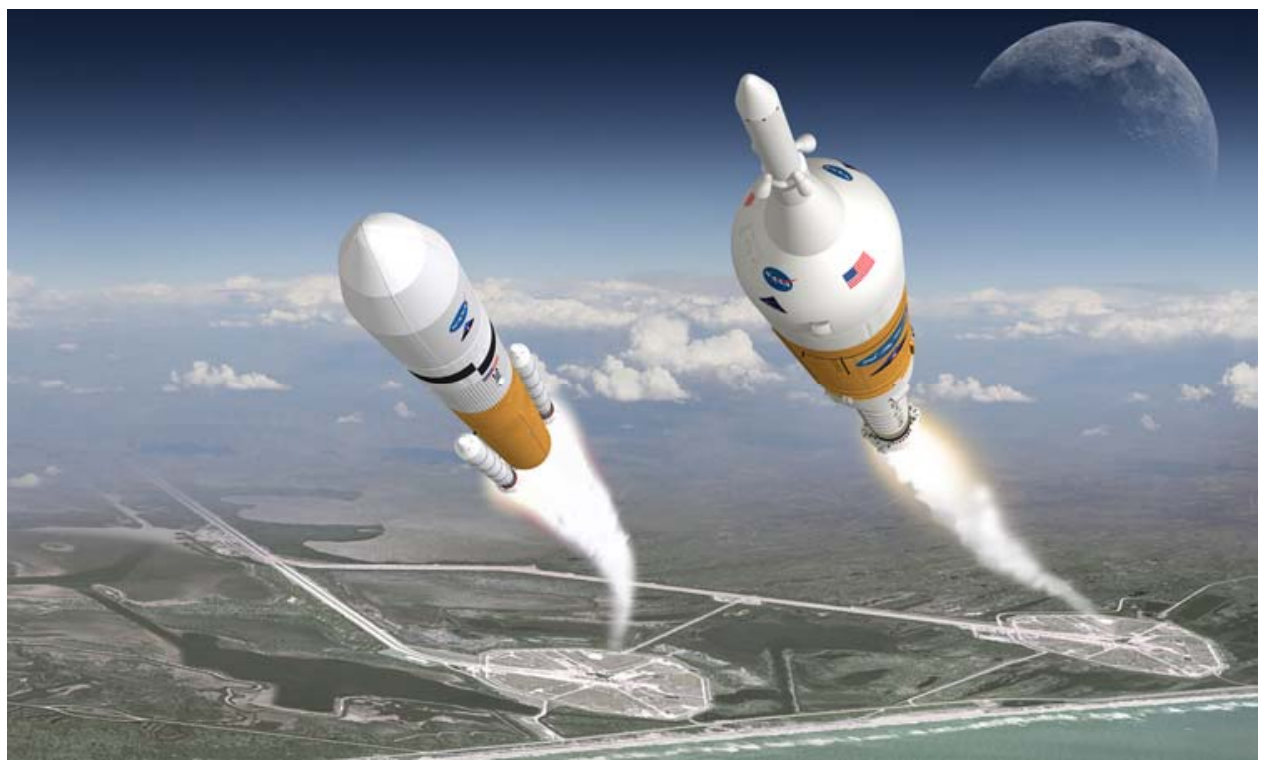

Figure 1. Ares V cargo launch vehicle (left) and Ares I crew launch vehicle (right). (NASA artist's concept)

\section{Design Overview}

The Ares I (Figure 2), which will be the first operational vehicle in the Ares fleet, consists of three major elements: a solid fuel first stage similar to a Shuttle reusable solid rocket booster (RSRB), an upper stage (US), and a liquid upper stage engine (USE). Based on the 4-segment solid rocket boosters (SRBs) of the Space Shuttle Program, the new 5-segment solid rocket booster configuration will produce over 3.5 million pounds of thrust at liftoff and provide reliable propulsion technologies that reduce development costs for future space missions. The additional thrust will allow the vehicle to lift more weight and reach a higher altitude before the first stage separates from the upper stage, to propel the Orion into low-Earth orbit.

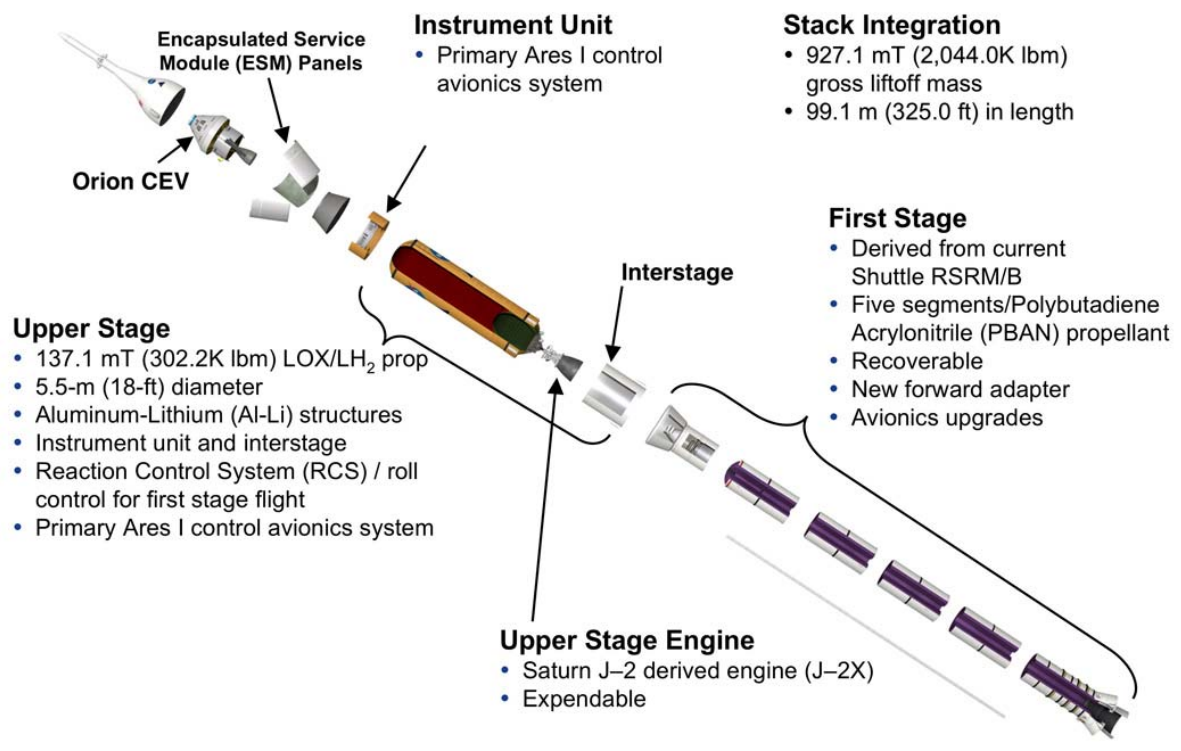

Figure 2. Ares I Launch Vehicle. 
The Ares V (Figure 3) cargo launch vehicle's propulsion system consists of a core stage and two boosters, which will be similar to those of the Ares I First Stage. With five commercial RS-68 engines (adapted from the Delta IV program) and the two five-segment solid rocket boosters, Ares V, which will begin full-scale development after the Shuttle's retirement, will be the largest launch vehicle ever built and will generate over 10.5 million pounds of thrust at liftoff. Ares V will launch the Earth departure stage (EDS) into orbit, where it will await the launch and docking of an Orion crew vehicle before providing a trans-lunar injection (TLI) burn.

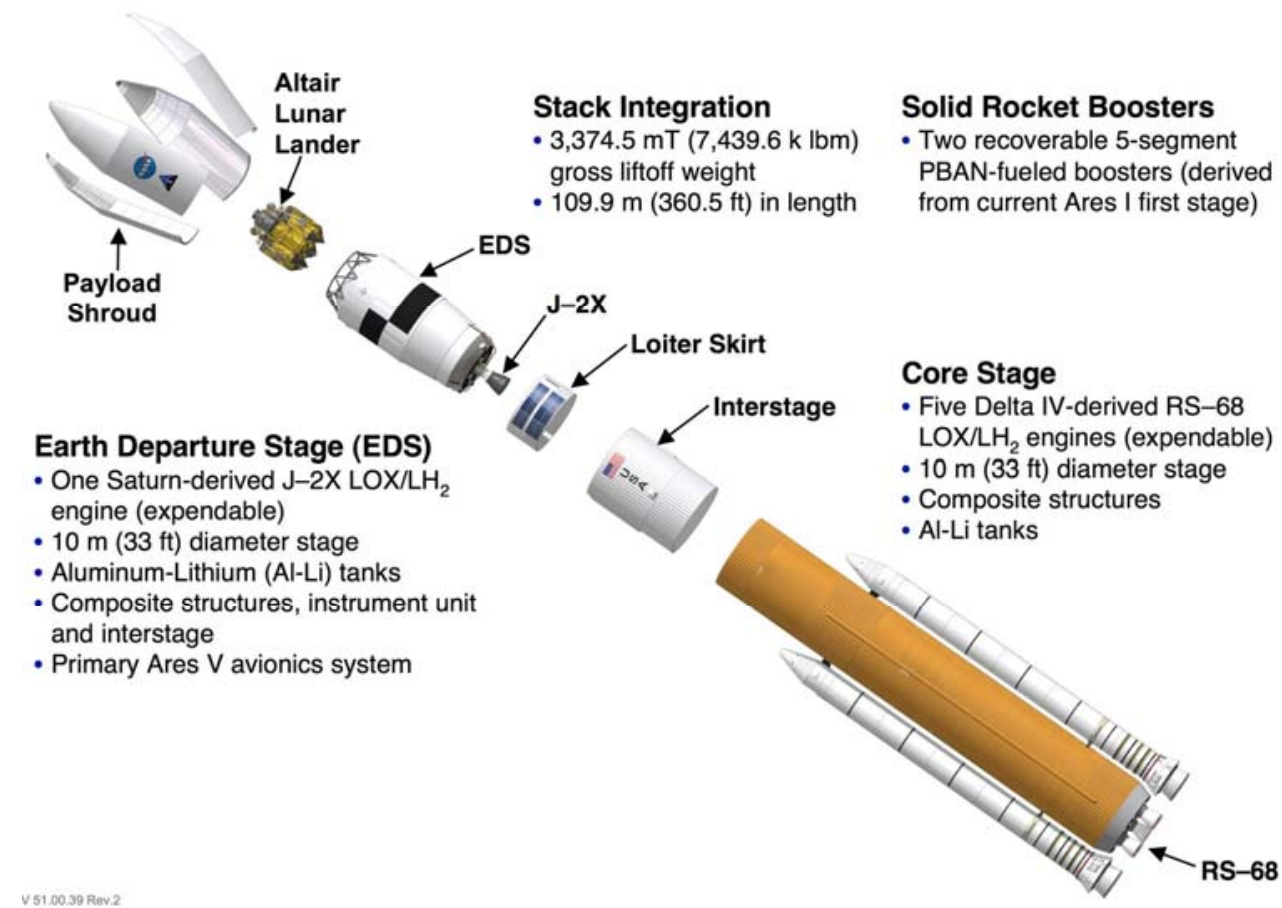

Figure 3. Ares V Cargo Launch Vehicle.

\section{Reusability Studies}

By using the same five-segment solid rocket boosters for Ares I and Ares V and a common solid motor design for both vehicles, data derived from the Ares I program can reduce the amount of effort required to prepare these boosters for the Ares V. While the legacy hardware is important, the Ares First Stage team is also upgrading the solid rocket boosters with state-of-the-art avionics, new hardware structures, and a redesigned nozzle. To that end, the First Stage office has conducted extensive expendability trade studies as part of life cycle cost evaluations.

One of the more important studies to date was conducted to determine the utility of flying the first stage as an expendable booster rather than making it reusable. The overall objective of this study was, specifically, to perform a life cycle cost study to evaluate expendable vs. reusable Ares I First Stage and Ares V solid rocket boosters (SRBs). The study used a complex cost model that provided comprehensive data for the Ares Projects to make a reliable decision regarding this vehicle element. This assessment included an evaluation of development, reliability, performance, and transition impacts associated with an expendable solution. Additionally, there have been a number of evaluations looking at approaches to enhancing the overall performance improvements for Ares boosters as a block upgrade to support Ares V and lunar missions.

To lower reusability study complexity, four operational scenarios, or cases, were defined. These included: Case 0 , Case I, Case II, and Case III. The study participants then defined the hardware configurations, which allowed performance, cost, and reliability to be assessed. An evaluation of the individual cases was completed in the context of several key assumptions that are likely unique to this program. The most significant was that a substantial quantity of hardware already existed and therefore an initial procurement was not required. The individual cases are defined below. 


\section{The Cases}

\section{A. Case 0}

Case 0 was the baseline reference case, which was to recover and reuse the first stage, which uses much of the current solid rocket booster legacy hardware; the Ares I hardware would be interchangeable with Ares V; Ares V would use legacy forward structures from the Space Shuttle inventory; and the solid rocket boosters would be recovered and inspected post flight and refurbished for a future flight. All other cases were associated with expendable configurations.

\section{B. Case I}

Case I assumed that the Ares Projects would fly out the current metal part inventory and eventually replace it with new hardware of the same design. Booster tumble motors (BTMs) would be eliminated, as would recovery systems and the forward skirt extension, as well as pyrotechnic and recovery systems. These changes assume that there would be no recovery on the first or subsequent test flights. A Case I booster would have one-time-use avionics; be designed for ascent, but not reentry/splashdown; incorporate thermal protection systems (TPS) for ascent only; and have all systems used for reentry/splashdown and recovery removed.

\section{Case II}

In Case II, solid rocket boosters would be recovered on the first seven flights in order to obtain post flight inspection (PFI) data and then convert to an expendable solution similar to Case I. It would maintain the outer moldline with the forward skirt extension to minimize vehicle data certification; and subsequent flights of Ares I and all flights of Ares V would use expendable booster hardware. Seven flights were chosen to provide sufficient data to evaluate internal insulation performance, namely to determine any flight-induced bias regarding insulation performance. All systems used for reentry/splashdown and recovery would be flown for the first seven flights. Under this case, Ares would fly out the existing metal hardware and replace it with new hardware of the same design. Hardware for the first seven flights is the same as Case 0 for reverse zero specific design items (e.g., thermal protection systems).

\section{Case III}

Case III is a complement to Cases I and II. Case I would fly until the metal hardware inventory is expended and replaced with expendable hardware. This would amount to a block upgrade of the booster hardware. Such an upgrade would be designed for ascent, but not reentry/splashdown. The new design would make extensive use of composites on the forward structures, aft structures, and case cylinders. With the forward skirt extension and main parachute support system removed, the first stage booster would be shorter than its current configuration. However, for Ares V, the design change would not result in shortened core stage attach points. The important figures of merit used to judge expendability versus reusability are cost, reliability, and performance.

This trade study was important because it encompassed the recurring and non-recurring life-cycle costs associated with facilities, ground support equipment (GSE), recovery ships, manufacturing, sustaining engineering, and refurbishment engineering. Table 1 depicts, at a high level, some of the advantages and disadvantages of each course of action. The most important disadvantage for expendability was the increased costs associated with hardware procurements. Those costs significantly exceeded the savings gained in facilities and operations.

Table 1. Advantages and disadvantages of expendability vs. reusability.

\begin{tabular}{|c|c|c|}
\hline & Advantage(s) & Disadvantage(s) \\
\hline Reusable & $\begin{array}{l}\text { - Ability to evaluate hardware post-flight } \\
\text { - Reduced hardware costs }\end{array}$ & $\begin{array}{l}\text { - Mass } \\
\text { - Higher operating costs }\end{array}$ \\
\hline Expendable & $\begin{array}{l}\text { - Would not require parachutes or forward } \\
\text { skirt extension - Mass } \\
\text { - Booster tumble motors (BTMs) or } \\
\text { thermal protection systems (TPS) not } \\
\text { required - Mass }\end{array}$ & $\begin{array}{l}\text { - New hardware costs } \\
\text { - Loss of post-flight data }\end{array}$ \\
\hline
\end{tabular}




\begin{tabular}{|l|l|l|}
\hline & Advantage(s) & Disadvantage(s) \\
\hline & $\begin{array}{c}\text { Pyrotechnic events and hardware } \\
\text { components reduced } \\
\text { - Reduced operations }\end{array}$ & \\
\hline
\end{tabular}

\section{Cost}

The study developed and populated a cost model using Case I, Case II, and Case III information. Costs for Case 0 were derived from the First Stage Element Office’s Program Planning and Budget Execution (PPB\&E) submission and then converted into constant 2008 dollars. This data was then extended to match the 2040 life cycle cost mission model. Costs for Cases I, II, and III were captured in constant 2008 dollars and then measured against Case 0 to determine any deltas (changes) from Case 0 . Data included:

- Hardware costs.

o Proposal values for new hardware, escalated actuals for legacy.

o Filament wound case based on Titan costs.

- Non-recurring cost for hardware vendor certification and delta qualification.

o ATK and USA provided.

- KSC and Clearfield facility operations and maintenance (O\&M) and ground support equipment (GSE) cost reductions.

o Florida facility inputs from KSC budget estimates.

- Recovery ships operations, maintenance, training and periodic dry dock.

o Actuals.

- Post-flight inspection cost elimination.

o Touch labor, safety and quality.

0 Actuals.

- Design Engineering reduction costs.

o Refurb and post-flight issue dispositioning.

o Refurb touch.

The cost model did not include:

- Economic value for performance increase.

- Transfer of cost deleted from first stage to other NASA projects for ships and Hangar-N (at KSC).

Case 0 proved to be the most effective alternative in the cost evaluation process for this specific situation. Cases I and II were the next-most cost-effective alternatives, and their total new equipment costs outweighed any facility cost savings by nearly a two-to-one margin, with increased costs measuring in the billions. Case III was less affordable than Cases I and II.

\section{A. Costs Summary}

Cumulative delta cost savings realized from elimination of recovery/refurb facilities, tooling, labor, engineering through 2018 timeframe include the cost of replacement hardware overcomes savings in the 2018 timeframe. The lifecycle delta cost increase is several billion dollars for expendability solutions. Consequently, if cost is the driving requirement, then the reuse solution has the lowest lifecycle cost through 2038.

\section{Reliability}

To evaluate the potential impacts on first stage reliability, post-flight evaluation data from 1988 through 2007 was evaluated along with current Shuttle Failure Modes and Effects Analysis (FMEA) database. The post-flight data (Figure 4) proved to be the most useful in determining the potential reliability impact to an expendable solution. 


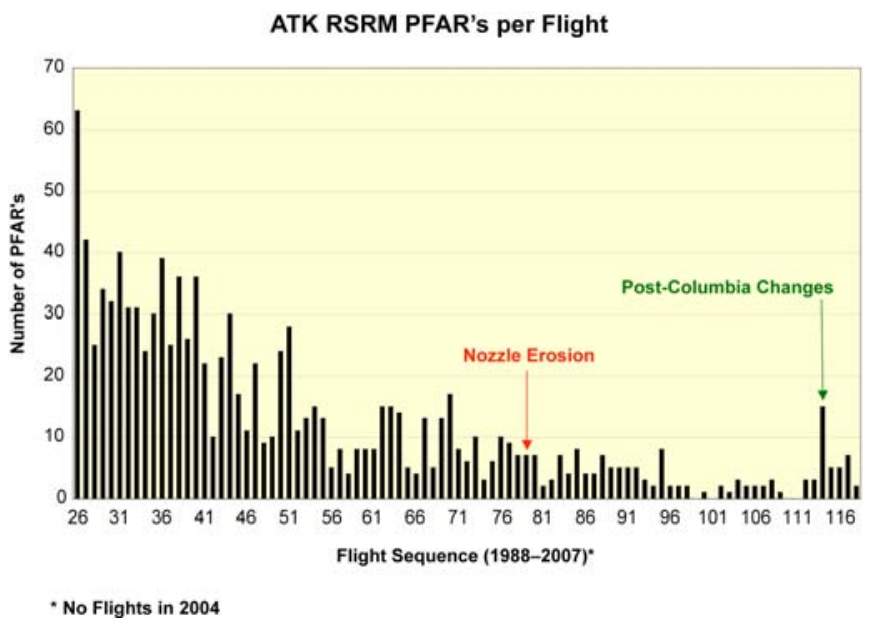

Figure 4. RSRM Post Flight Assessment Report Trend.

By looking back, filtering the data through a series of questions, the first stage team was able to see how many critical performance issues may have had the potential to propagate to a booster failure. See Figure 5 for the screening methodology. ${ }^{5}$

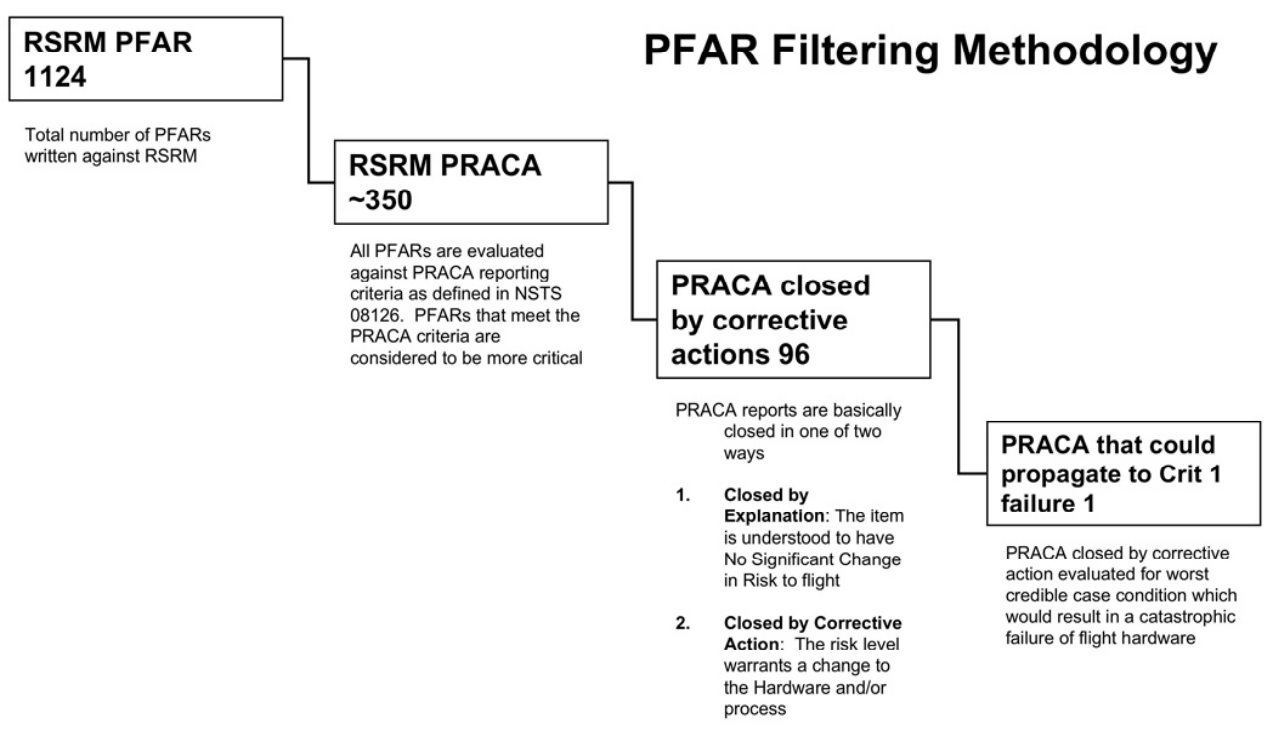

Figure 5. RSRM Post-Flight Assessment Report (PFAR) Screening Process.

${ }^{5}$ The process began (upper left corner of the figure) with all the initial post flight inspection (PFI) data found in Post Flight Assessment Reports (PFAR). These reports were then screened against the criteria for entering the data into NASA's problem tracking system, PRACA, the Problem Assessment and Corrective Action System. A total of 1124 PFARs were evaluated against the PRACA reporting criteria. These 350 screened PRACA reports were then grouped into two categories:

1. PRACA reports closed by explanation - the item is understood to have no significant change in risk to flight;

2. PRACA reports closed by corrective action - the risk level warranted a change to the hardware and/or process.

This screening step found a total of 96 (updated) reports to have been closed by corrective action. These reports were then further evaluated for potential catastrophic effect of the problem on the vehicle, called Crit 1 in the NASA community, had the RSRM not been recovered to allow PFI and problem discovery. (Safie) 
By determining the number of potential Crit $1^{6}$ anomalies, probabilistic analyses could be performed. These data are presented in the following two tables.

Table 2. Crit 1 Items = 1, First Stage Impact 6.5\%.

\begin{tabular}{|c|c|c|c|c|c|c|}
\multirow{2}{*}{ TPM } & \multicolumn{3}{|c|}{ First Stage } & \multicolumn{3}{c|}{ Ares I } \\
\cline { 3 - 7 } & \multirow{2}{*}{ Requirement } & \multicolumn{2}{c|}{ Estimates } & \multirow{2}{*}{ Requirement } & \multicolumn{2}{c|}{ Estimates } \\
\cline { 3 - 7 } & & Case 0 & Case I & & Case 0 & Case I \\
\hline LOM & $1 / 1,675^{*}$ & $1 / 1,200 *$ & $1 / 1,126$ & $1 / 500^{*}$ & $1 / 358^{*}$ & $1 / 351$ \\
\hline LOC & $1 / 11,000$ & $1 / 8,000$ & $1 / 7,510$ & $1 / 3,200$ & $1 / 2,386$ & $1 / 2,339$ \\
\hline
\end{tabular}

Table 3. Reliability Results: Crit 1 Items = 2, First Stage Impact 13\%.

\begin{tabular}{|c|c|c|c|c|c|c|}
\hline \multirow{2}{*}{ TPM } & \multicolumn{3}{|c|}{ First Stage } & \multicolumn{3}{c|}{ Ares I } \\
\cline { 3 - 7 } & \multirow{2}{*}{ Requirement } & \multicolumn{2}{c|}{ Estimates } & \multirow{2}{*}{ Requirement } & \multicolumn{2}{c|}{ Estimates } \\
\cline { 3 - 7 } & & Case 0 & Case I & & Case 0 & Case I \\
\hline LOM & $1 / 1,675^{*}$ & $1 / 1,200^{*}$ & $1 / 1,062$ & $1 / 500$ & $1 / 358^{*}$ & $1 / 344$ \\
\hline LOC & $1 / 11,000$ & $1 / 8,000$ & $1 / 7,000$ & $1 / 3,200$ & $1 / 2,386$ & $1 / 2,294$ \\
\hline
\end{tabular}

The reliability decrease with an expendable design (due to loss of post-flight data) was assessed to be between 6.5 and 13 percent. The post-flight data analyses were useful in categorizing the items typically seen, such as design causes, manufacturing causes, supplier causes, and processing causes. These 350 PRACA reports are graphed in Figure 6 and presented in pie chart format in Figure 7.

\section{Design Causes}

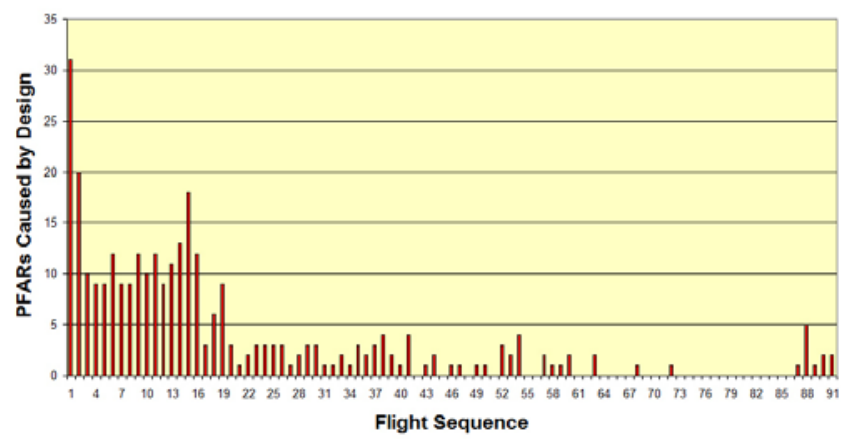

\section{Manufacturing Causes}

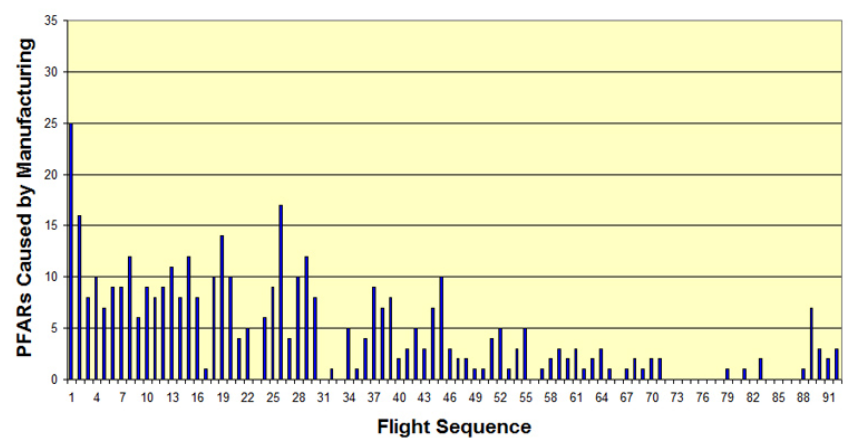

\footnotetext{
${ }^{6} \mathrm{~A}$ critical, level 1 failure, which could result in loss of mission (LOM) or loss of crew (LOC).
} 


\section{Supplier Causes}

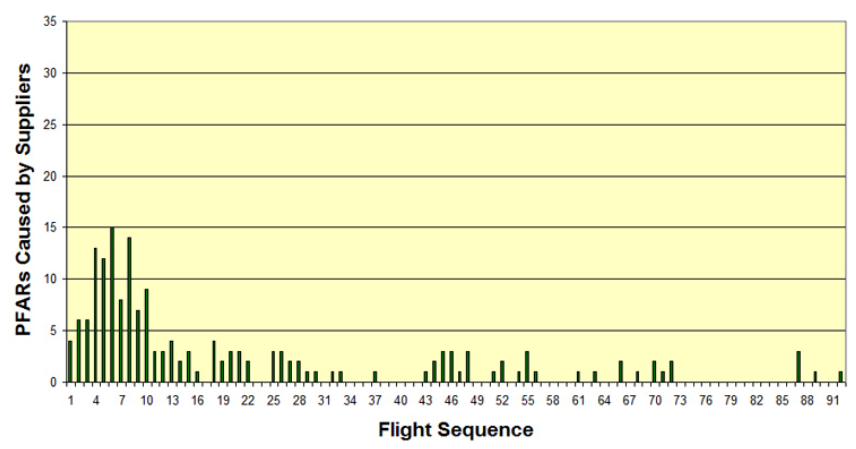

\section{Processing Causes}

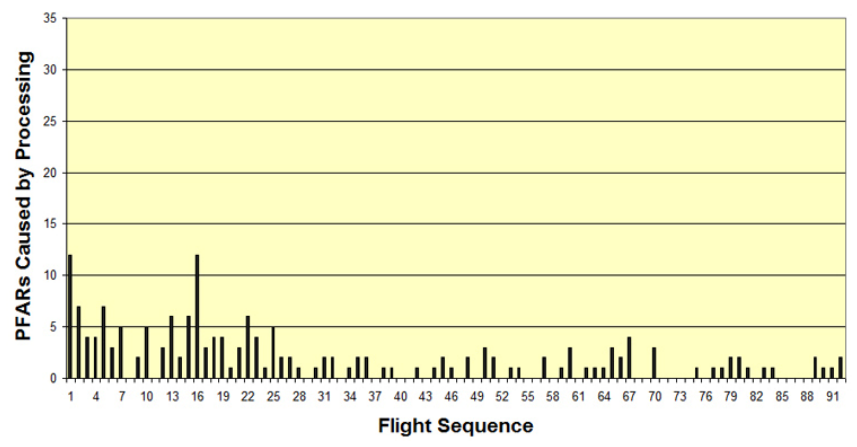

Figure 6. RSRM Post Flight Assessment Report Causes by Category. ${ }^{7}$

It is apparent in these data, that many of the issues regarding first stage performance anomalies have been significantly reduced over time. This trend demonstrates the robustness and maturation of this large solid rocket motor, giving first stage designers confidence in their ability to create a five-segment design drawing on over 20 years of post-flight assessment.

Hazard impacts were evaluated based on current Shuttle solid rocket booster failure modes and effects analysis (FMEA) hazards. These data were evaluated to determine which failure modes could be eliminated with the elimination of deceleration, recovery, and reuse design items. Most of the reduction in failure modes was attributed to pyrotechnic "fail to fire" or "premature fire" of these systems. By eliminating these failure modes, the total reduction in first stage Crit 1 failure modes equaled 21 percent, a seemingly large number. However, due to the high reliability of such systems, the overall effect on first stage reliability was insignificant. An example of a potential Crit 1 failure is shown in Table $4 .^{8}$

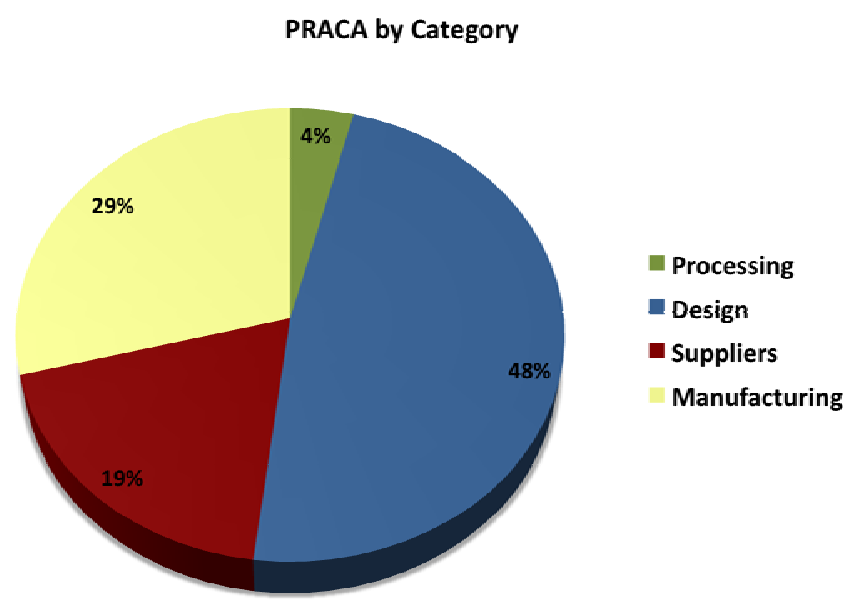

Figure 7. RSRM Post Flight Problem Assessment and Corrective Action Reports by Category.

\footnotetext{
${ }^{7}$ The spike that appears on the right of the charts is a result of changing inspection ground rules due to the Columbia accident.

${ }^{8}$ The pocket erosion on the reusable solid rocket motor throat and forward exit cone described in Table 4 occurred during pre-Challenger years and then again in 1996 on reusable solid rocket motor-56B, which was flown on Space Shuttle flight 79. Later it was observed in 2001 during static testing. Nozzle composite parts have demonstrated a high sensitivity to change over the years. The cause for the pocketing was attributed to an oven at a second tier supplier. Processing creep, the unintended and unobserved change in critical process parameters over time, occurred with the oven, which led to the pocketing. Without post flight evaluation, the probability of detection for this issue would have been extremely low.
} 
Table 4. Example of a Potential Crit 1.

\begin{tabular}{|c|c|c|c|c|c|}
\hline STS & FLT & Date & RSRM & Title & Summary \\
\hline 79 & 79 & 9/16/1996 & $56 \mathrm{~B}$ & $\begin{array}{l}\text { Abnormal } \\
\text { Carbon } \\
\text { Phenolic } \\
\text { Erosion Pattern } \\
\text { on Nozzle } \\
\text { Throat Ring and } \\
\text { Forward Exit } \\
\text { Cone, RSRM- } \\
\text { 56B* }\end{array}$ & $\begin{array}{l}\text { SPR 292, RSRM-56B pocket erosion on the } \\
\text { throat and forward exit cone CCP (and } \\
\text { erosion/char margin of safety violations) may be } \\
\text { attributed to ply-angles and wrinkles in throat aft } \\
\text { end. RSRM-49 also had pocket erosion on the } \\
\text { throat and FEC (and erosion/char margin of safety } \\
\text { violations). Minor pocketing was also reported on } \\
\text { RSRM-57B. See deviation RDW-0652. Adequate } \\
\text { margins of safety allow for pocketing. A spacer } \\
\text { augmented mandrel - allows for overstock and } \\
\text { removal of any ply distortions - was incorporated. } \\
\text { Plasma torch test bed (PTTB) sampling of aft tag } \\
\text { ends and laser hardening material evaluation tab } \\
\text { (LHMEL) tests - when necessary -- help prevent } \\
\text { phenoloic material that may have a higher } \\
\text { propensity to pocket. See PAS } 301 \text {. }\end{array}$ \\
\hline
\end{tabular}

The team also evaluated impacts to ground hazards and the potential for reducing them through expendability. These hazards included dangers to the ground crew during recovery; shipboard incidents; and refurbishment hazards at KSC and ATK Launch Systems facilities such as processing hazards related to pyrotechnic and other recovery hardware.

\section{B. Reliability Summary}

PFA screening found one item that could have propagated to Crit 1 if left unattended. The corresponding calculated decrease on first stage reliability is 6.5 percent, from 1 chance in 1,200 to 1 in 1,126 for loss of mission (LOM). A significant number of design issues were corrected as a result of post-flight findings. By going with an expendable booster, a total of 81 (21 percent) Crit 1 failure modes could be eliminated from the nozzle, separation, deceleration and recovery subsystems; these included low-probability events with insignificant affect on reliability calculations. Ground hazards were reduced by eliminating recovery, refurbishment, and processing. There was a new hazard with potential shipping lane debris. Filament wound case (FWC) hazards need detailed assessment.

Given the maturity of the solid rocket booster (in great part due to the benefits gained from 30 years of inspection), and given that the design modifications for Ares First Stage will be certified via static test, post-flight data alone does not justify recovery. Current Ares design changes can be adequately evaluated with a robust ground static test program. Increased developmental flight instrumentation (DFI) will provide a marginal impact on performance understanding: Flight bias on insulation performance. Increased ground testing, process control, material fingerprinting, etc., will have greater impact on reliability.

In essence, it was concluded that some reliability impacts would result from losing post-flight inspection data but that the decision regarding expendability was driven mostly by the lifecycle cost and need for performance.

\section{Performance}

A Systems Panel Team performed vehicle performance calculations concentrating on the amount of additional payload Ares I and Ares V could carry to low-Earth orbit (LEO) in each of the primary three cases. A brief discussion of each of the configurations, weight changes, and payload performance of those three cases follow: (Blackwell)

\section{A. Ares I, Case I Performance Study:}

There is a payload gain opportunity if the Ares I First Stage is not designed for recovery and the hardware components required for recovery and reusability of the first stage are removed. The current Ares I First Stage 
design is configured for recovery of the first stage booster hardware after launch. The booster hardware is recovered, cleaned for shipment at Hangar AF, and re-furbished for re-use at ATK or KSC. The forward skirt extension assembly is removed and the first stage outer mold-line (OML) is shortened. This option is viable if the Ares I vehicle can accommodate the increased dynamic pressure and accelerations during first stage flight due to the lighter vehicle. The first stage weight change for expendability is estimated to be 22,300 pounds less than the recoverable variant. The weights are based on an analysis by ATK, the Ares First Stage team, Ares, and Shuttle reusable solid rocket booster projects. The first stage motor type hardware weighs 3,110 pounds less and the non-motor type hardware is 19,190 pounds less. The Ares I ascent performance change is estimated at 2,100 pounds more. The change in maximum dynamic pressure is estimated to be an increase of 21 pounds per square foot.

\section{B. Ares I, Case II Performance Study:}

There is a potential payload gain opportunity if the Ares I first stage is not recovered on "selected" flights and the hardware components required for recovery and reusability of the first stage are removed. The forward skirt extension assembly is not removed to maintain the first stage outer mold-line. If recovery is desired, the hardware may be re-installed. If recovery is selected, there is zero change to performance. The "selected recovery" option is viable if the Ares I vehicle can accommodate the increased dynamic pressure and accelerations during first stage flight. The first stage weight change for "selective recovery" is about 16,910 pounds less. The weights are based upon an analysis by ATK, the Ares First Stage team, Ares, and Shuttle reusable solid rocket booster projects. The first stage motor type hardware is 3,110 pounds less and the non-motor type hardware is 13,800 pounds less. The Ares I ascent performance change is estimated at 1,600 pounds more. The change in maximum dynamic pressure is estimated as a 16 pound per square foot increase.

\section{Ares I, Case III Performance Study:}

There is a larger payload gain opportunity if the Ares I First Stage is not designed for recovery and the current first stage hardware components are redesigned for performance. The first stage weight is reduced by replacing part of the steel case components with graphite composite components. The forward skirt extension assembly is removed and the first stage outer mold-line is shortened. This option is viable if the Ares I vehicle can accommodate the increased dynamic pressure and accelerations during first stage flight due to the lighter vehicle. The first stage weight change is estimated to be 58,920 pounds less. The weights are based upon an analysis by ATK, the Ares First Stage team, Ares, and Shuttle reusable solid rocket booster projects. The first stage motor type hardware is 39,710 pounds less and the non-motor type hardware is 19,210 pounds less. The weight change estimate is derived assuming no mass growth allowance. The Ares I ascent performance change is estimated as 5,550 pounds greater. The change in maximum dynamic pressure is estimated at a 56 pound per square foot increase.

\section{Ares I, Cases I, II, and III Performance Increase - Case Maximum Expected Operating Pressure (MEOP) Increase:}

For the three Ares I cases, there is an additional potential payload gain opportunity if the first stage is not recovered for reuse and a higher propellant burn rate is selected. The first stage steel case MEOP may be raised to 1,066 pounds per square inch absolute from 1,016 pounds per square inch absolute if only used for one flight. This increase allows the propellant burn rate to be increased by about 10.4 mills. This option is viable if the Ares I vehicle can accommodate the increased dynamic pressure and accelerations during first stage flight. The Ares I ascent performance change is estimated as 2,010 pounds greater. The change in maximum dynamic pressure is estimated as an 80 pound per square foot increase.

\section{E. Ares V, Case I Performance Study:}

There is a payload gain opportunity if the Ares V first stage is not designed for recovery and the hardware components required for recovery and reusability of the first stage are removed. The First Stage outer mold-line is unchanged. This option is viable if the Ares $\mathrm{V}$ vehicle can accommodate the increased dynamic pressure and accelerations during first stage flight due to the lighter vehicle. The first stage weight change is estimated to be 15,810 pounds less. The weights are based upon an analysis by ATK, Ares First Stage Project, Ares Project, and Shuttle reusable solid rocket booster project. The first stage motor type hardware is 2,960 pounds less and the nonmotor type hardware is 12,850 pounds less. The Ares $\mathrm{V}$ ascent performance change is estimated as 2,720 pounds more. The change in maximum dynamic pressure is estimated as a 6 pound per square foot increase. 


\section{F. Ares V, Case III Performance Study:}

There is a larger payload gain opportunity if the Ares V First Stage is not designed for recovery and the current first stage hardware components are redesigned for performance. The first stage weight is reduced by replacing part of the steel case components with graphite composite components. The forward skirt assembly is redesigned and the first stage outer mold-line is changed. This option is viable if the Ares V vehicle can accommodate the increased dynamic pressure and accelerations during first stage flight due to the lighter vehicle. The first stage weight change is estimated to be 56,270 pounds less. The weights are based upon an analysis by ATK, the Ares First Stage team, Ares, and Shuttle reusable solid rocket booster projects. The first stage motor type hardware is 39,560 pounds less and the non-motor type hardware is 16,710 pounds less. The weight change estimate is derived assuming no mass growth allowance. The Ares $\mathrm{V}$ ascent performance change is estimated as 9,700 pounds more. The change in maximum dynamic pressure is estimated as a 20 pound per square foot increase.

\section{G. Ares V, Cases I, and III Performance Increase - Case Maximum Expected Operating Pressure (MEOP) Increase:}

For both cases, there is an additional potential payload gain opportunity if the first stage is not recovered for reuse and a higher propellant burn rate is selected. The first stage steel case MEOP may be raised to 1,066 pounds per square inch absolute (psia) from 1,016 pounds per square inch absolute if only used for one flight. This increase allows the propellant burn rate to be increased by about 10.4 mills. This option is viable if the Ares $\mathrm{V}$ vehicle can accommodate the increased dynamic pressure and accelerations during first stage flight. The Ares I ascent performance change is estimated as 6,380 pounds more. The change in maximum dynamic pressure is estimated as an increase of 50 pounds per square foot.

Vehicle performance calculations were completed by the Systems Panel Team. Tables 5 and 6 depict these predicted results.

Table 5. Potential performance increases for Ares I based on the three cases.

\begin{tabular}{|c|c|c|} 
Case & $\begin{array}{c}\text { Additional Payload } \\
\text { (pounds of } \\
\text { mass/lbm) }\end{array}$ & $\begin{array}{c}\text { Delta in Maximum Dynamic } \\
\text { Pressure (pounds per square } \\
\text { foot/psf) }\end{array}$ \\
\hline I & 2,100 & +21 \\
\hline II & 0 and 1,600 & +16 \\
\hline III & 5,550 & +56 \\
\hline
\end{tabular}

Notes:

- Additional performance potential is possible with a maximum expected operating pressure (MEOP) increase from 1,016 pounds per square inch (psi) to 1,066 pounds per square inch. The MEOP increase would be allowable because the hardware would not be reused in Cases I-III.

- Addition of 2,010 pounds of mass for Cases I, II, III (delta max Q = 136 pounds per square foot).

Table 6. Potential performance increases for Ares $V$ based on the three cases.

\begin{tabular}{|c|c|c|} 
Case & $\begin{array}{c}\text { Additional Payload } \\
\text { (pounds of } \\
\text { mass/lbm.) }\end{array}$ & $\begin{array}{c}\text { Delta in Maximum Dynamic } \\
\text { Pressure (pounds per square } \\
\text { foot/psf) }\end{array}$ \\
\hline I & 2,725 & +6 \\
\hline II & N/A & N/A \\
\hline III & 9,700 & +20 \\
\hline
\end{tabular}




\section{Notes:}

- Case II stipulated a gradual ramp-up toward expendable hardware as a block upgrade for Ares I. In the case of Ares V, expendable hardware would be used from the start; thus, Case II was not included as a scenario for Ares V.

- Additional performance potential is possible with a MEOP increase from 1,016 pounds per square inch to 1,066 pounds per square inch. The MEOP increase would be allowable because the hardware would not be reused in Cases I and III.

- $\quad$ Addition of 6,380 pounds of mass for Cases I and III (delta max $Q=+70$ pounds per square foot).

\section{H. Performance Summary}

The performance difference between Case I and Case III was 2,100 to 5,550 pounds of mass (lbm) respectively for Ares 1, depending on the expendability design solution. There was a 2,725 to 9,700 pounds of mass performance increase between Case I and Case III for Ares V depending on the expendability design solution. Consequently, if performance is the driving requirement, then expendability provides significant performance benefits:

- $\quad 2,100$ to 5,500 pounds of mass for Ares I.

- 2,725 to 9,700 pounds of mass for Ares $V$.

\section{Reusability Studies Conclusion}

If cost is the only determining factor, the Ares First Stage reusability study provided enough data for the Ares Projects to make a reliable decision regarding this vehicle element. The most important finding was that it is not lifecycle-cost effective to adopt expendable over reusable Ares I first stage and Ares V boosters. This solution is driven by the need for performance. However, if performance remains an issue for Ares I and V, then expendability provides measurable performance benefits, albeit at significant cost to the project.

- $\quad 2,100$ to 5,500 pounds of mass for Ares I.

- $\quad 2,725$ to 9,700 pounds of mass for Ares V.

The effect of the absence of PFI data does not drive this decision; however, it will have a small affect on first stage reliability. The assessment is subjective in evaluating Crit 1 hazard propagation and does not include combination interactions. With an expendable solution, the First Stage Element Office would need to conduct the following activities to reexamine the issue and ensure booster quality and safety:

- Increased manufacturing and operations inspection and surveillance, material finger printing (quality tracking), etc.

- Increased numbers and extremes on static testing.

With this study completed, the Ares First Stage team is moving forward with its plans to reuse the solid rocket boosters as part of NASA's continuing commitment to safe, reliable, and affordable space transportation activities.

\section{Acknowledgements}

For assistance in writing this paper:

Bart Leahy, Sr. Technical Writer

Schafer Corporation

Regina Garson, Technical Writer

TRAX, International

\section{References}

Reports, and Individual Papers 
${ }^{1}$ Priskos, Alex, and Williams, Thomas J., “Growing the First Stage of the Ares Launch Vehicles,” 2007 Joint Propulsion Conference, Hartford, CN.

${ }^{2}$ Safie, Fayssal M., PhD, Weldon, Danny M. “Evaluation of Space Shuttle Solid Rocket Motor Recovery Data, A Lesson Learned for the Ares I Launch Vehicle.” NASA George C. Marshall Space Flight Center, Marshall Space Flight Center, Alabama 35812 .

${ }^{3}$ Sumrall, Phil, and Creech, Steve, “Refinements in the Design of the Ares V Cargo Launch Vehicle for NASA's Exploration Strategy,” Upcoming 2008 Joint Propulsion Conference, Hartford, CN.

${ }^{4}$ Williams, Thomas J., “Ares I First Stage Expendability Trade Study,” NASA George C. Marshall Space Flight Center, Marshall Space Flight Center, Alabama 35812.

${ }^{5}$ Williams, Tom, and Cannon, Scott, “Ares I First Stage Design, Development, Test, and Evaluation.” 57th International Astronautical Congress, 2-6 Oct. 2006, Valencia.

Interviews

${ }^{6}$ Blackwell, Douglas L., "Performance Case Studies,” Consultant, Systems Engineering, Lee and Associates, NASA George C. Marshall Space Flight Center, Marshall Space Flight Center, Alabama 35812. 


\title{
Reusability Studies for Ares I and Ares V Propulsion
}

\author{
Thomas J. Williams ${ }^{1}$ and Alex S. Priskos ${ }^{2}$ \\ NASA Marshall Space Flight Center, MSFC, AL, 35812 \\ Andrew A. Schorr ${ }^{3}$ \\ NASA Marshall Space Flight Center, MSFC, AL, 35812 \\ and \\ Gregory Barrett ${ }^{4}$ \\ NASA Marshall Space Flight Center, MSFC, AL, 35812
}

\begin{abstract}
With a mission to continue to support the goals of the International Space Station (ISS) and explore beyond Earth orbit, the United States National Aeronautics and Space Administration (NASA) is in the process of launching an entirely new space exploration initiative, the Constellation Program. Even as the Space Shuttle moves toward its final voyage, Constellation is building from nearly half a century of NASA spaceflight experience, and technological advances, including the legacy of Shuttle and earlier programs such as Apollo and the Saturn $V$ rocket. Out of Constellation will come two new launch vehicles: the Ares I crew launch vehicle and the Ares V cargo launch vehicle. With the initial goal to seamlessly continue where the Space Shuttle leaves off, Ares will firstly service the Space Station. Ultimately, however, the intent is to push further: to establish an outpost on the Moon, and then to explore other destinations. With significant experience and a strong foundation in aerospace, NASA is now progressing toward the final design of the First Stage propulsion system for the Ares I. The new launch vehicle design will considerably increase safety and reliability, reduce the cost of accessing space, and provide a viable growth path for human space exploration. To achieve these goals, NASA is taking advantage of Space Shuttle hardware, safety, reliability, and experience. With efforts to minimize technical risk and life-cycle costs, the First Stage office is again pulling from NASA's strong legacy in aerospace exploration and development, most specifically the Space Shuttle Program. Trade studies have been conducted to evaluate lifecycle costs, expendability, and risk reduction. While many first stage features have already been determined, these trade studies are helping to resolve the operational requisites and configuration of the first stage element. This paper first presents an overview of the Ares missions and the genesis of the Ares vehicle design. It then looks at one of the most important trade studies to date, the "Ares I First Stage Expendability Trade Study." The purpose of this study was to determine the utility of flying the first stage as an expendable booster rather than making it reusable. To lower the study complexity, four operational scenarios (or cases) were defined. This assessment then included an evaluation of the development, reliability, performance, and transition impacts associated with an expendable solution. The paper looks at these scenarios from the perspectives of cost, reliability, and performance. The presentation provides an overview of the paper.
\end{abstract}

\footnotetext{
${ }^{1}$ Propulsion Systems Manager, Ares Projects, MSFC, AL, 35812.

${ }^{2}$ First Stage Element Manager, Ares Projects, JP20, MSFC, AL, 35812.

${ }^{3}$ Lead, Ares First Stage Five Segment Motor (RSRMV), Ares Projects, JP20, MSFC, AL, 35812.

${ }^{4}$ FITO and Ares V Business Manager, Ares Projects, MSFC, AL, 35812.
} 


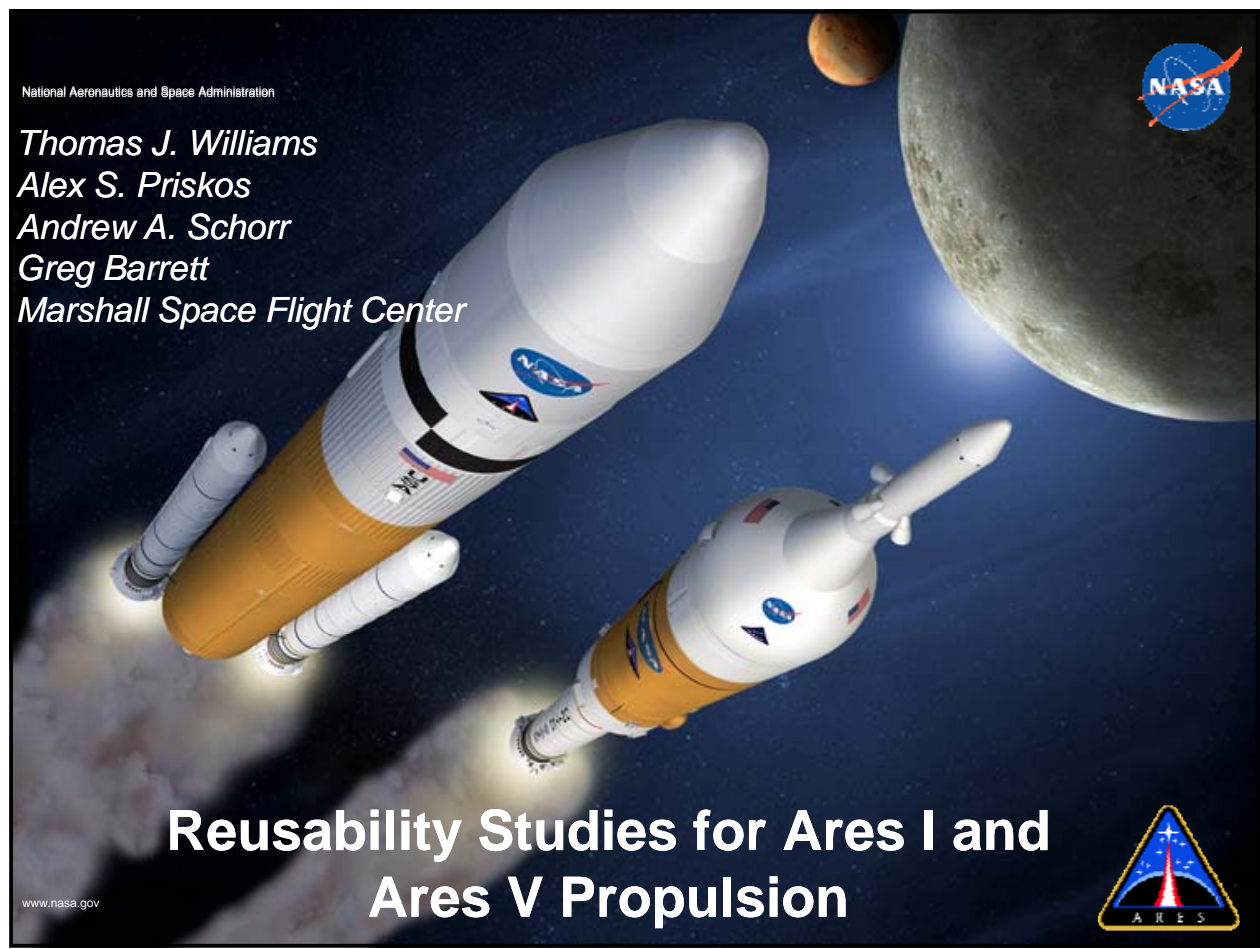

\section{Agenda}

- Introduction

- Ares Overview

- Ares First Stage Design Overview

- Reusability Studies

- The Cases

- Cost

- Reliability

- Screening Methodology

- Crit Items

- Post Flight Assessment Report Causes by Category

- Performance

- Conclusions 

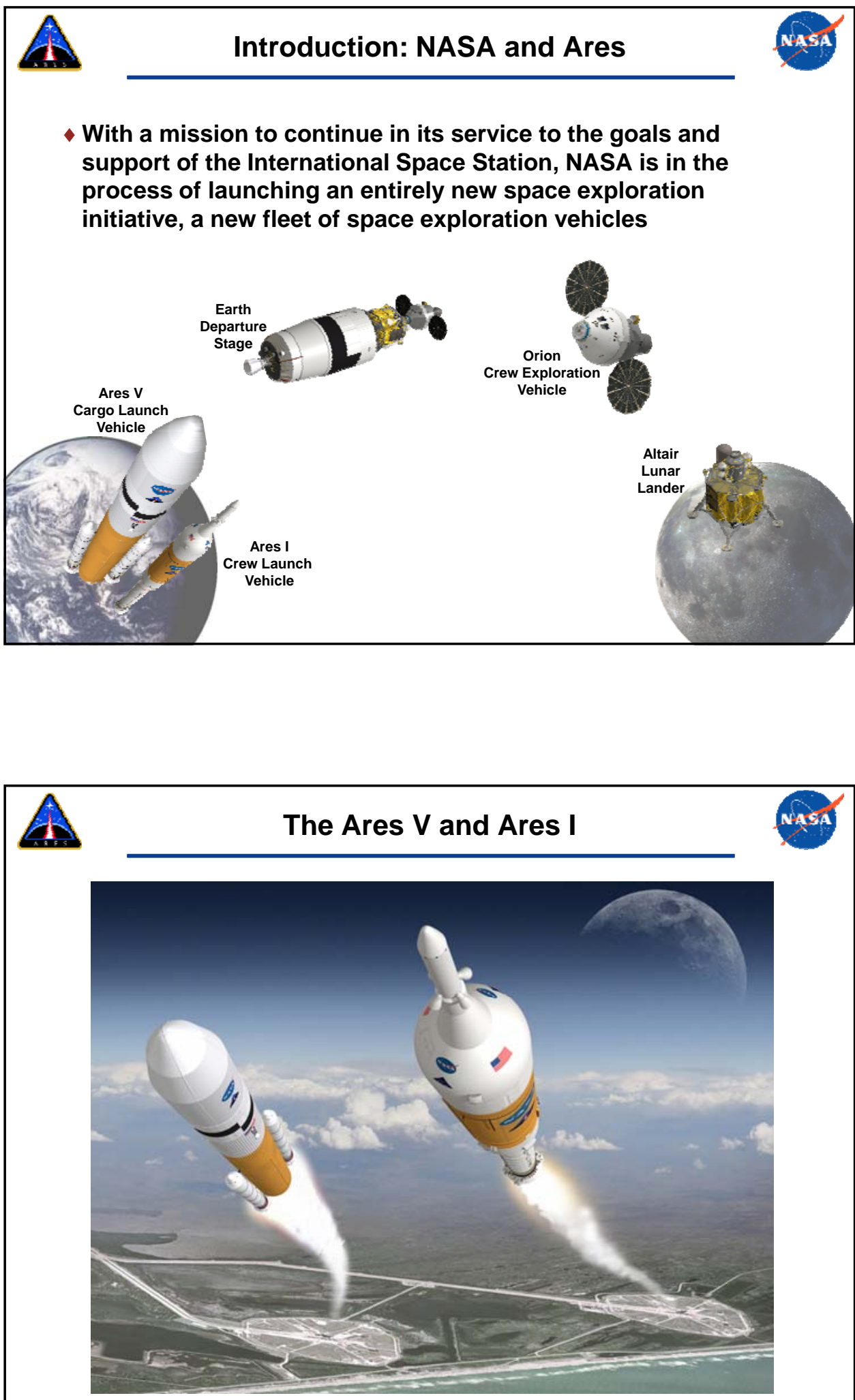

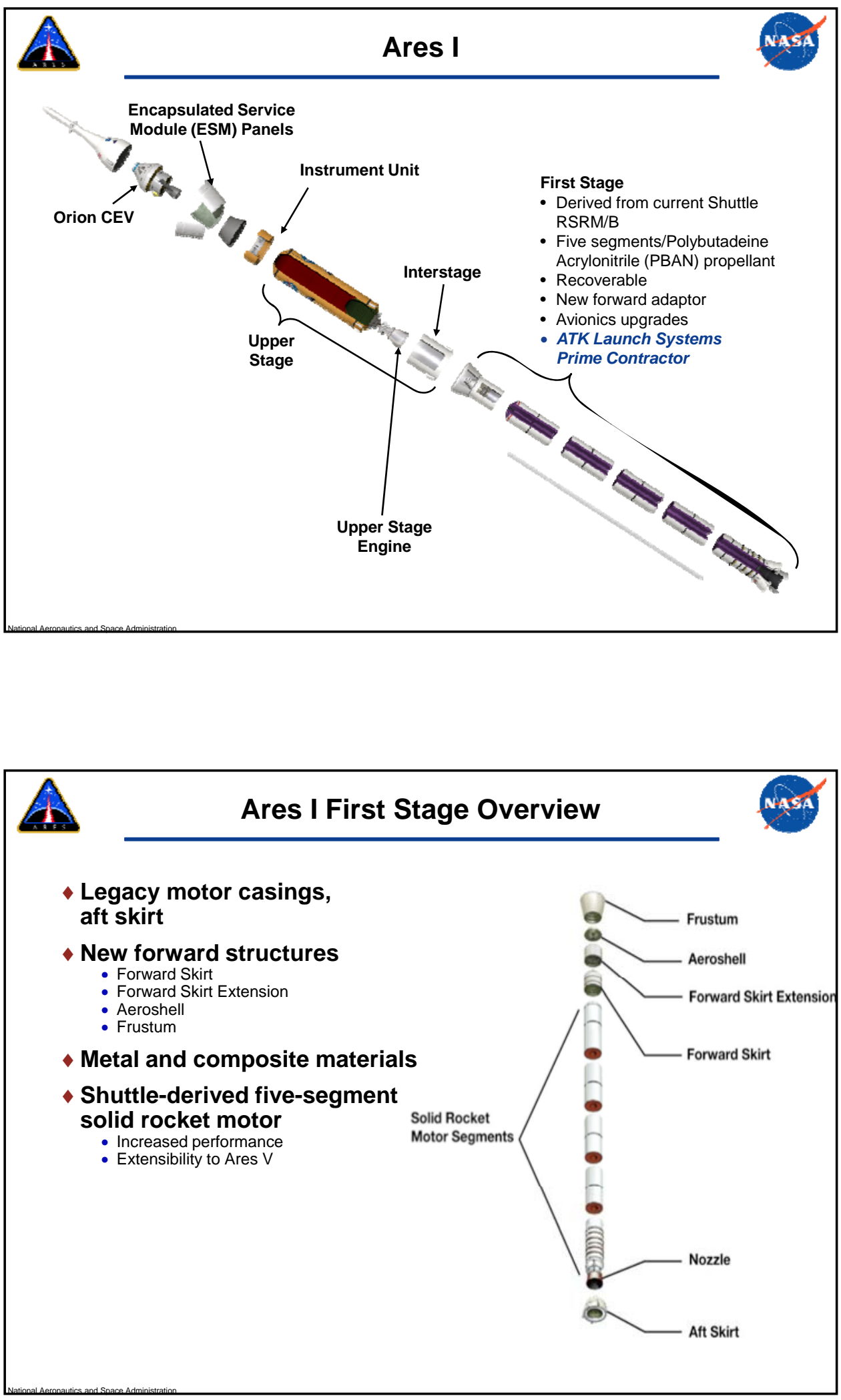


First Stage Expendability Introduction
Objective - Perform a life cycle cost
study to evaluate expendable vs. reuse
of the Ares I First Stage and Ares V Solid
Rocket Boosters.
This assessment will include an
evaluation of the technical impacts in
development, reliability, performance
and transition of an expendable vs.
reusable first stage solution

Study Cases
Case 0
- Baseline reference case
- Ares I hardware interchangeable with Ares $\mathrm{V}$
- Heritage forward structures for Ares $\mathrm{V}$
Case I
- Fly out current hardware and replace with current design
- Modified design for expendability
- No chutes, no fwd. skirt extension, no booster tumble motors, etc.
Case II
- Recover for 7 flights
- Driven by potential need for insulation flight performance bias
- Maintain outer mold line (fwd skirt extension = 5394 lbm) to minimize
vehicle delta certification
Case III
- Hardware with design for expendable application
- Implement for Ares $\mathrm{V}$ with block change on Ares I when first metal part
runs out




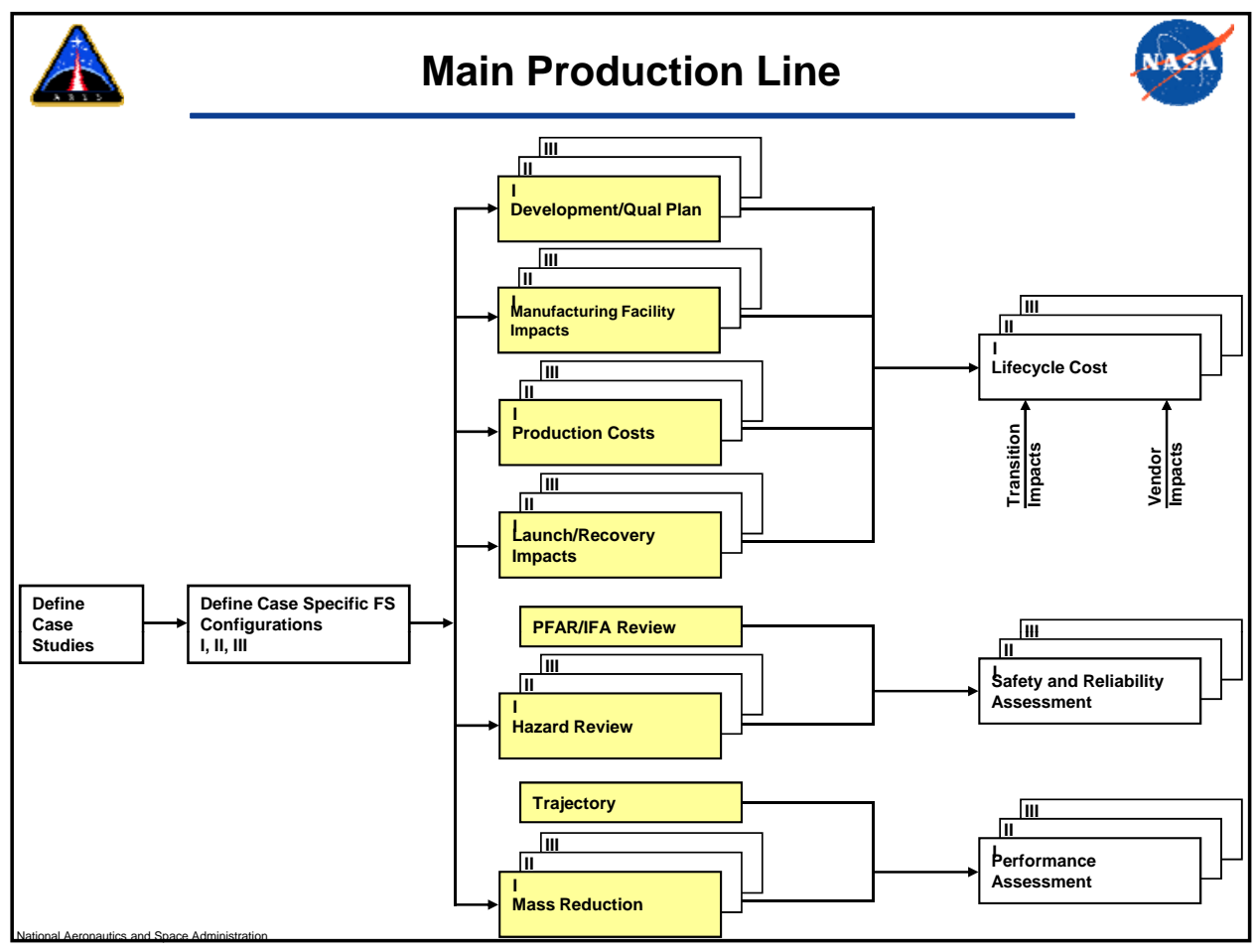

PPBE 09 Ares I and Ares V First Stage Flights and FSMs

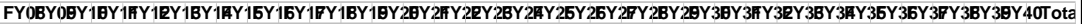

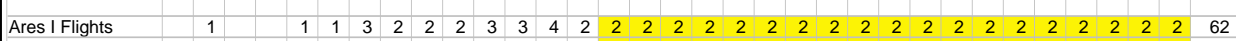
\begin{tabular}{l||llllllllllllllllllllllllll}
\hline Ares V Flights & 1 & 1 & 1 & 2 & 2 & 2 & 2 & 2 & 2 & 2 & 2 & 2 & 2 & 2 & 2 & 2 & 2 & 2 & 2 & 2 & 2 & 2 & 2 & 2 & 45
\end{tabular} 
- Cost model developed and populated with Case 1, Case 2 and Case 3 information

- Hardware Costs

- Proposal values for new hardware, escalated actuals for heritage, learning curve applied to account for high rate production (reduces average unit cost by $20-25 \%$ )

- FWC based on Titan costs escalated to FY08 constant dollars

- Non-recurring cost for hardware vendor certification and delta qualification - ATK and USA provided

- KSC and Clearfield facility O\&M and GSE cost reductions - Florida facility inputs from KSC budget estimates

- Recovery ships operations, maintenance, training and periodic dry dock - Actuals

- Elimination of refurbishment labor costs (Touch labor, Support and Quality)

- KSC (eliminated for Hanger A-F, Hanger N, and PRF)

- ATK (reduced Clearfield refurbishment substantially)

- 100 percent reduction of touch and support for refurbishment at KSC and 45 percent reduction of touch and support for refurbishment at ATK, cannot eliminate due to case hardware acceptance at Clearfield

- Based on KSC and ATK budget estimates

- Design Engineering reduction costs

- Refurb and postflight issue dispositioning

- 20 percent reduction of total engineering at USA and ATK

- Cost model does not include

- Economic value for performance increase

- Transfer of cost deleted from First Stage to other NASA projects for Ships and Hanger- $\mathrm{N}$

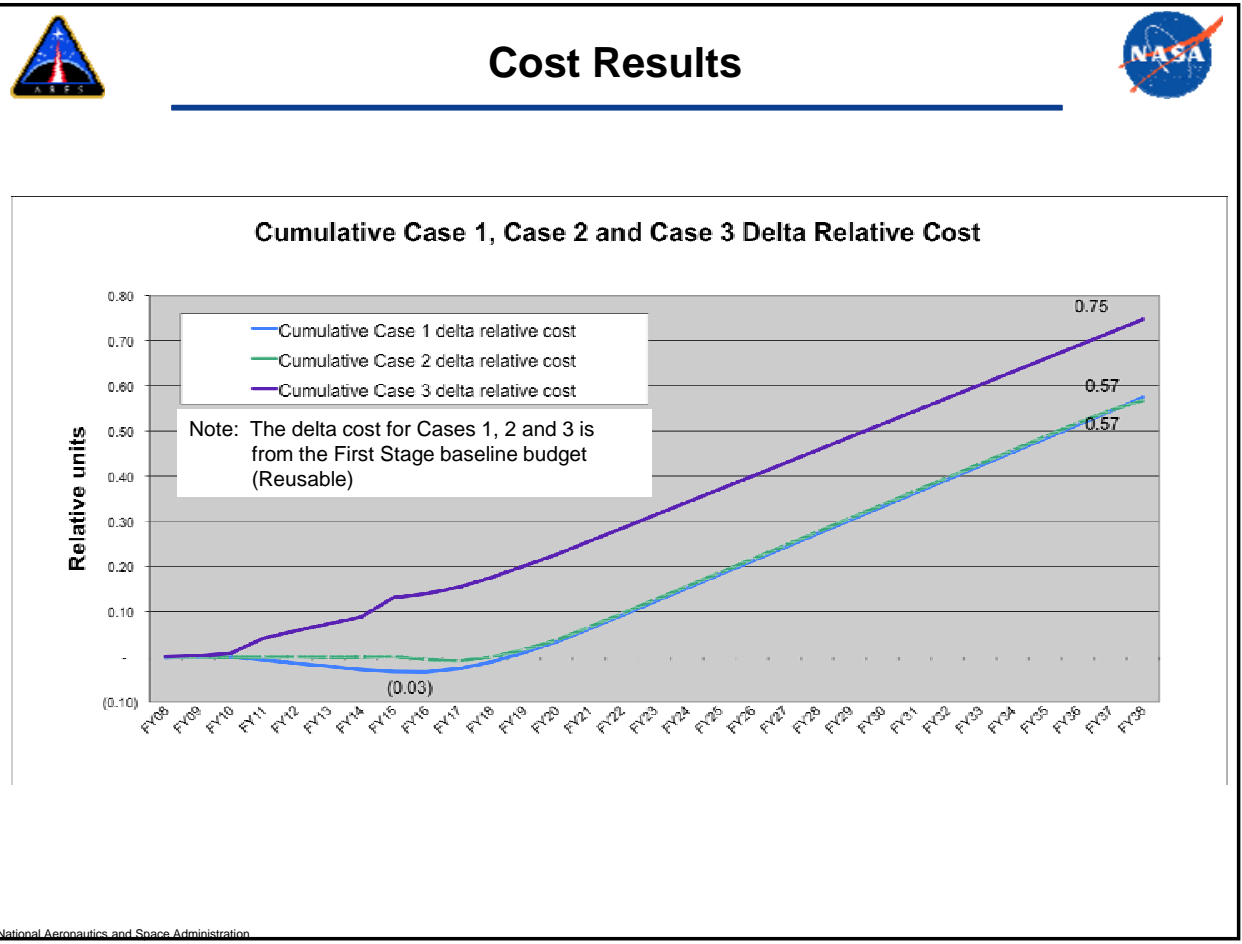



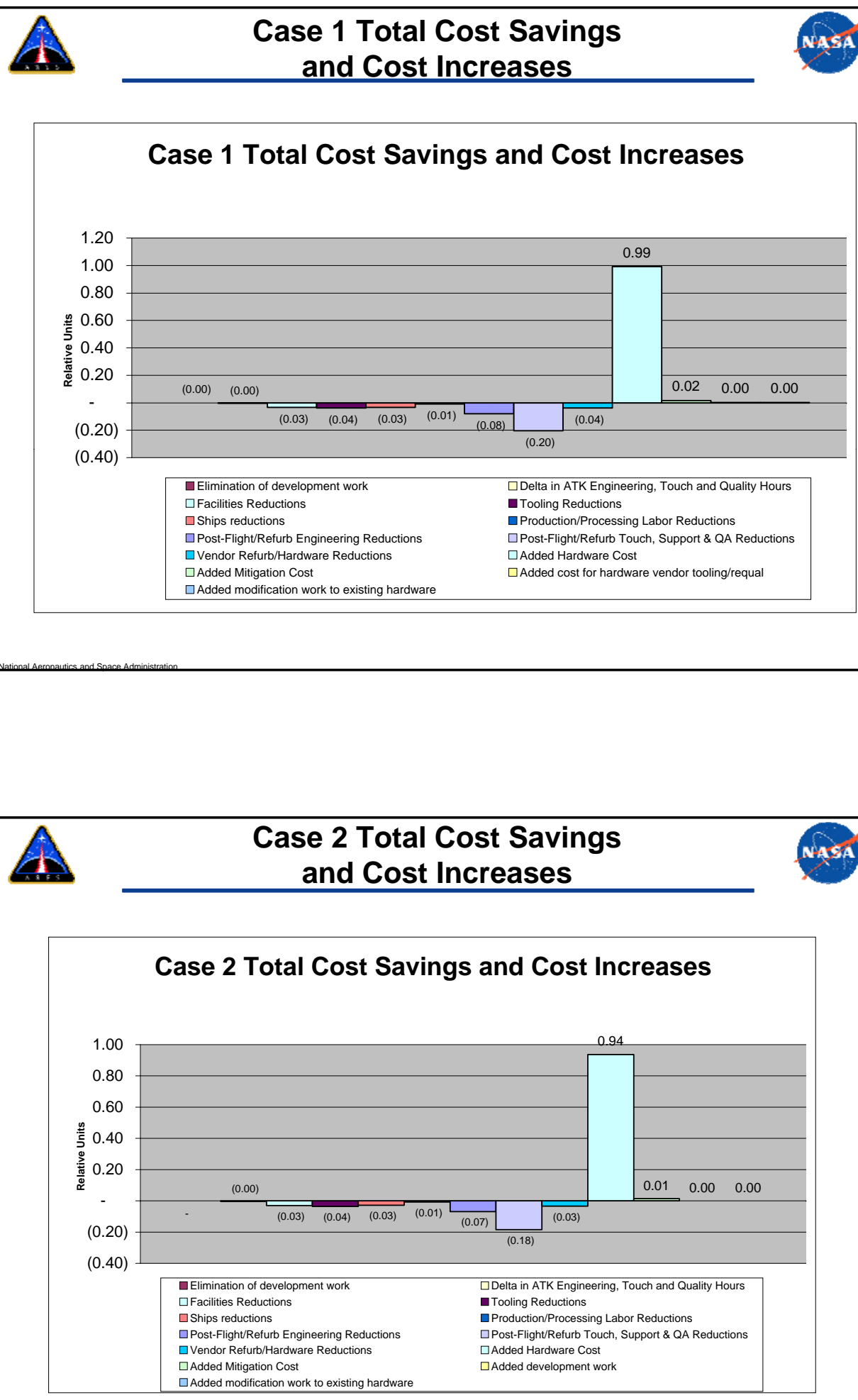


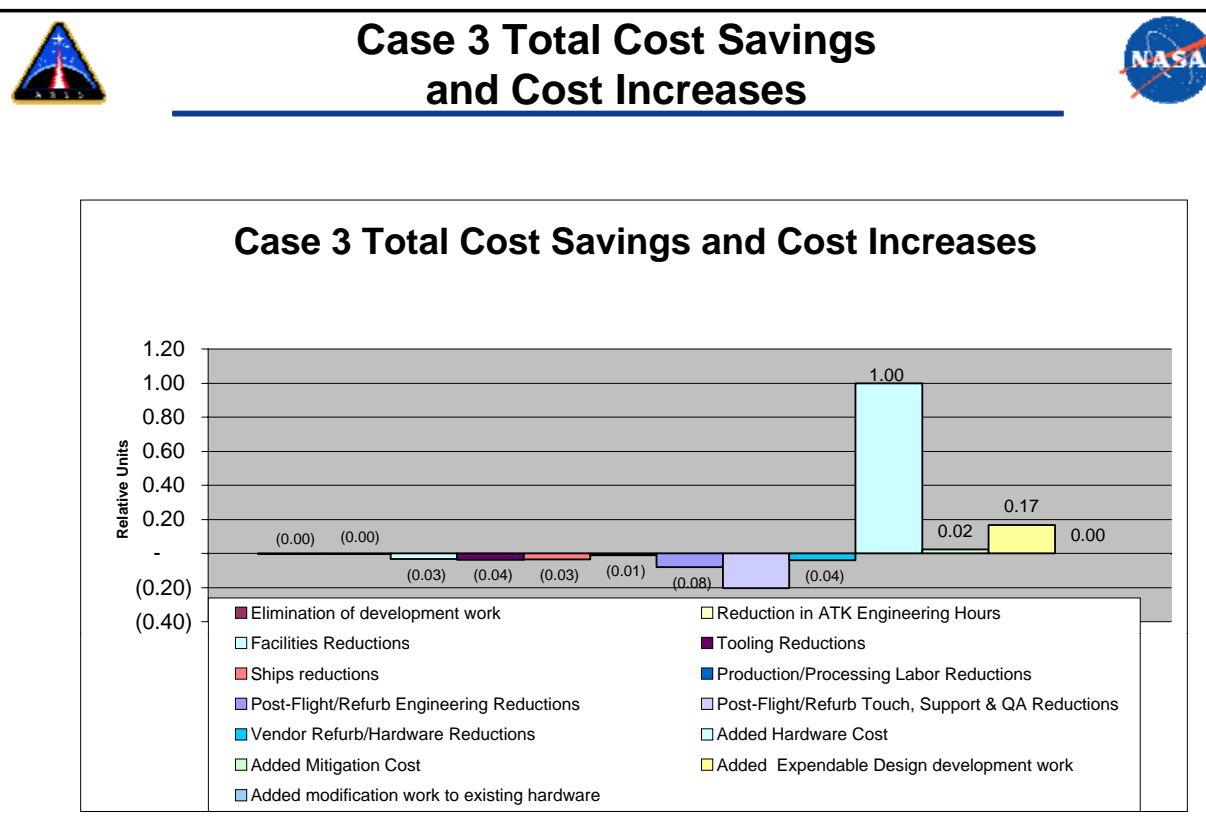

\section{A Safety and Reliability Assessment Process}

- Primary effort associated with evaluation of postflight inspection results (1988 - 2007)

- Screening methodology for items, if left unattended, could result in Crit 1

- Item(s) assigned probability and reliability impacts calculated

- Evaluated hazards impacts based on current Shuttle RSRB FMEA hazards

- Evaluated ground hazards impacts

- Cursory evaluation of Case III FWC impacts 

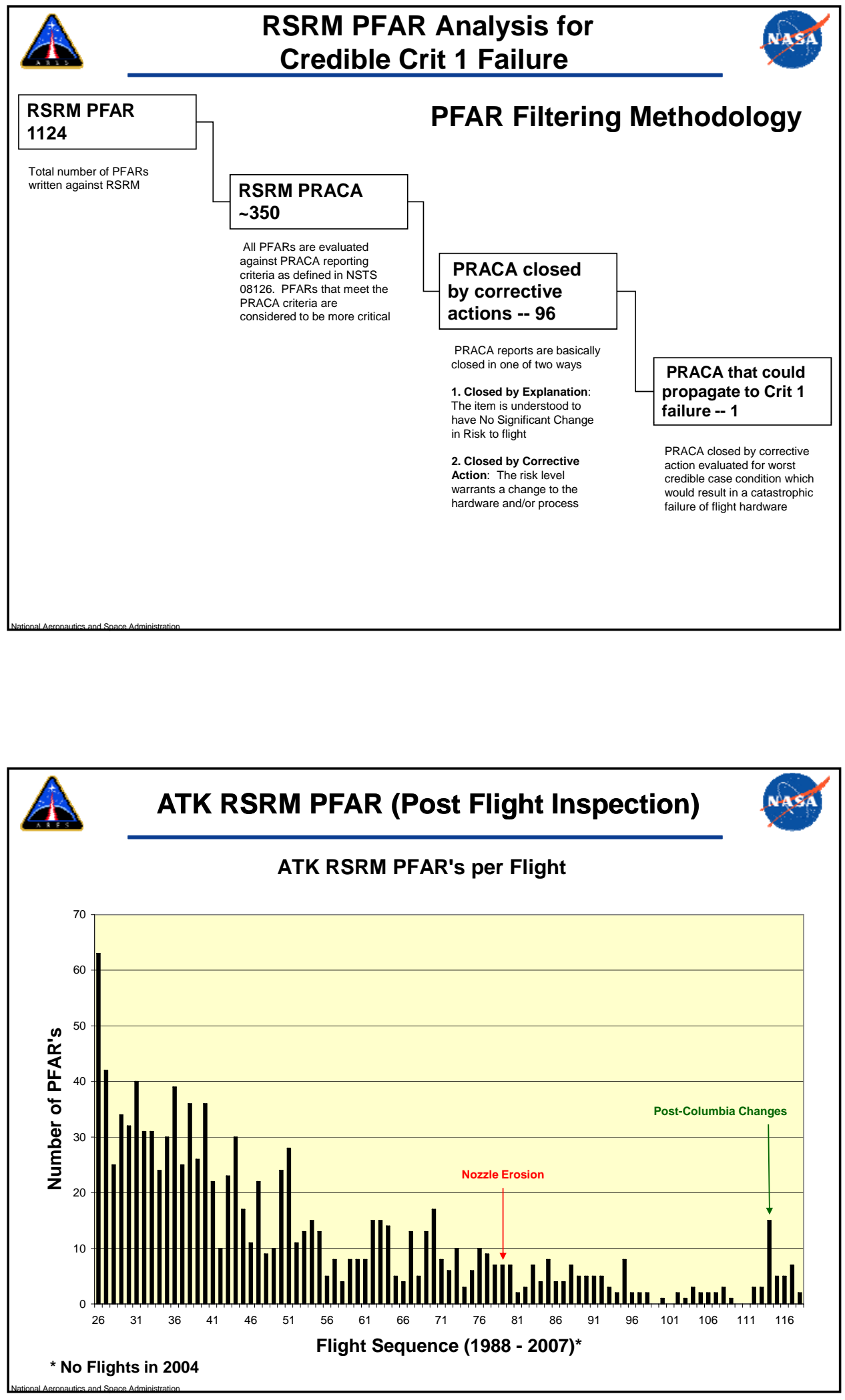

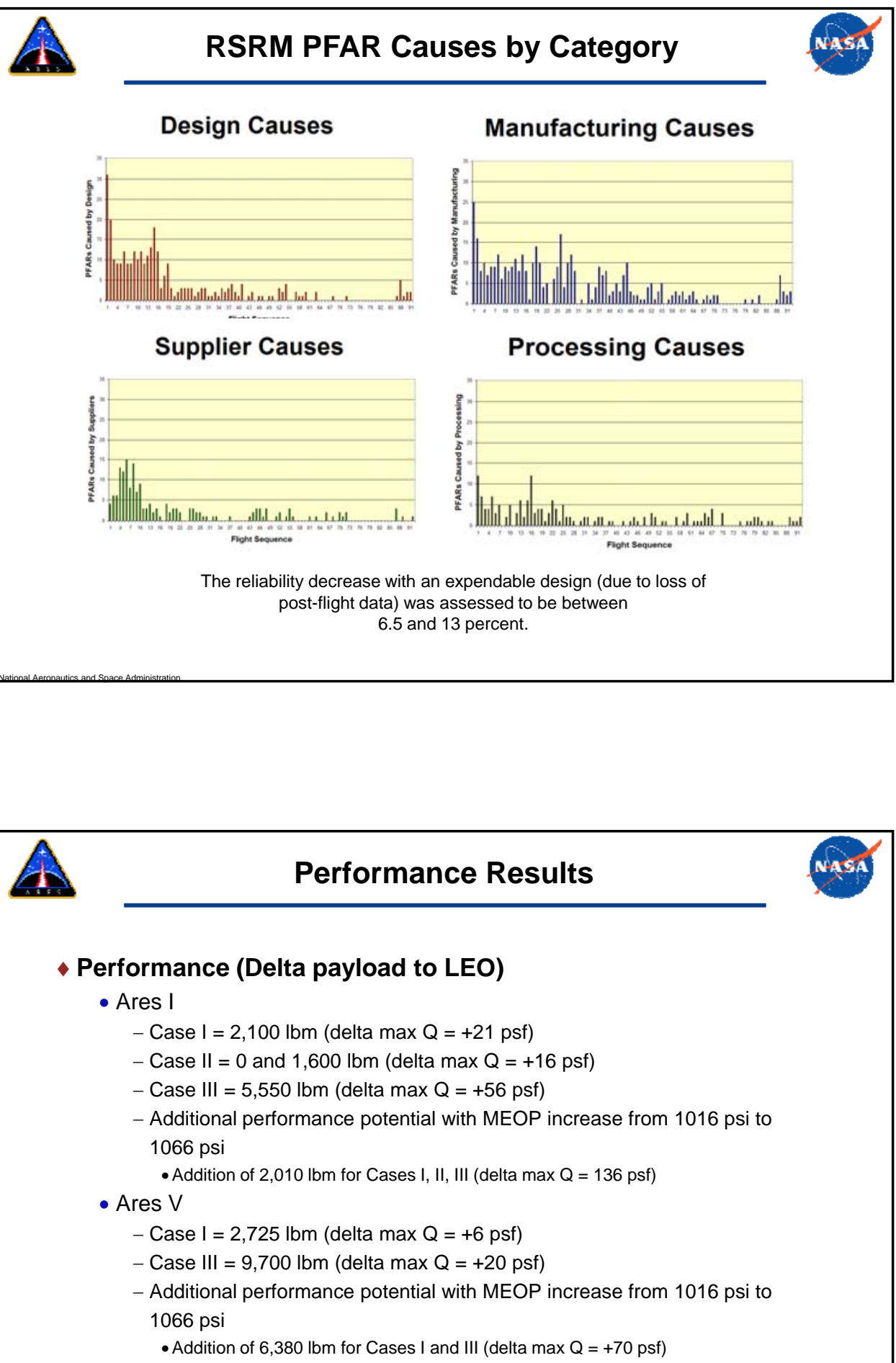


\section{Conclusions}

- It is not Life Cycle Cost effective to adopt expendable over reusable Ares I FS and Ares V Boosters

- The need for performance drives this solution (if required).

- If performance remains an issue for Ares I and V, then expendability provides measurable performance benefits but at significant cost

- 1,600 to $5,500 \mathrm{lbm}$ for Ares I

- 2,725 to $9700 \mathrm{lbm}$ for Ares $V$

- The effect of the absence of post flight inspection does not drive this decision, however, it will have a small affect on FS reliability

- Assessment is subjective in evaluating Crit. 1 propagation and does not include combination interactions

- With an expendable solution it is desirable to re-examine:

- Increased manufacturing and operations inspection and surveillance, material finger printing, etc

- Increased numbers and extremes on static testing

- The Team has completed the objective to evaluate the life cycle cost of expendable vs. reuse of the Ares I First Stage and Ares V Solid Rocket Boosters

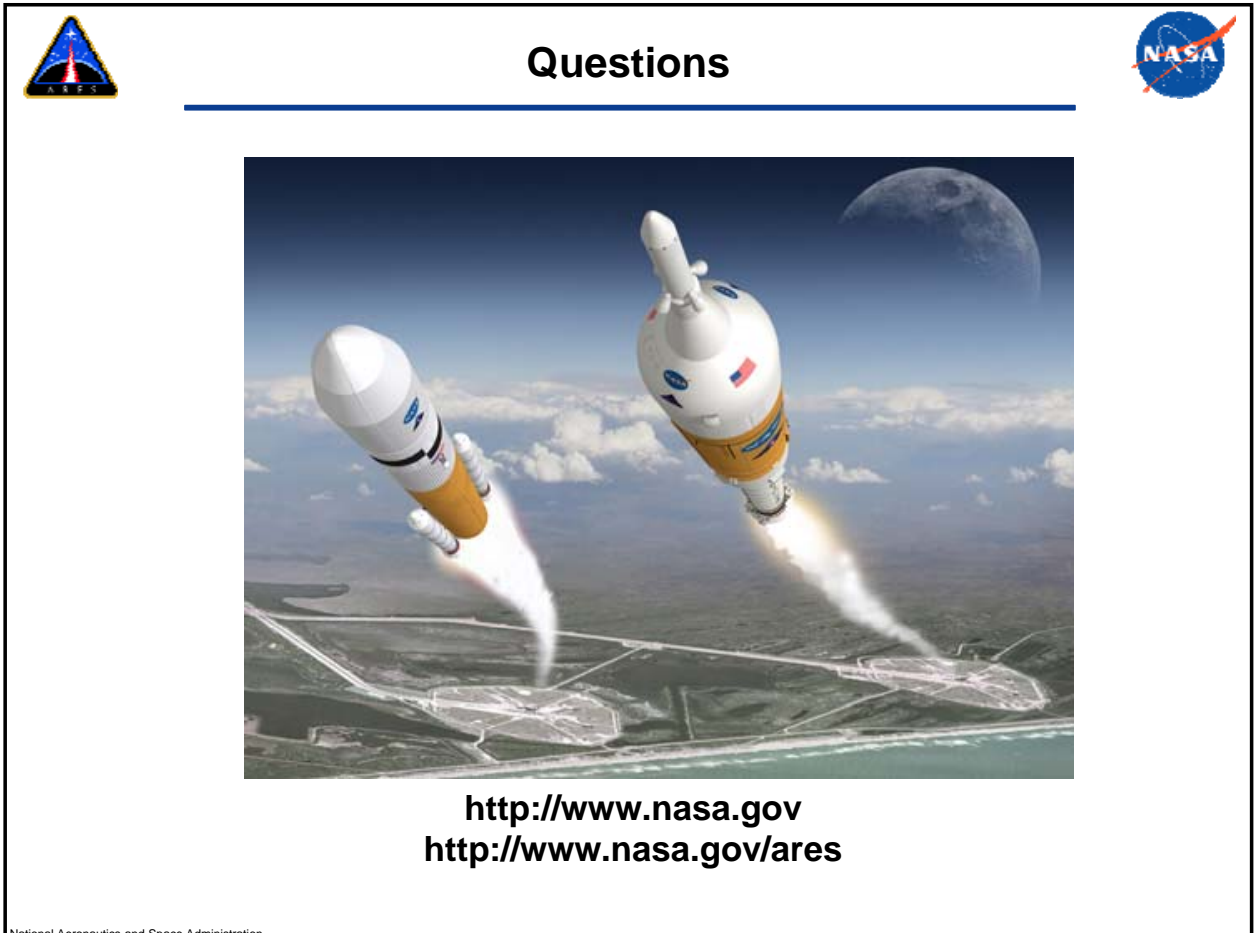

